\title{
O REVOLUCIONÁRIO DIRETOR DO INPA - OBITUÁRIO \\ PAULO DE ALMEIDA MACHADO, 18/7/1916 - 13/11/1991
}

Antonio de Azevedo Correa $\left({ }^{1}\right)$

Paulo de Almeida Machado, nasceu na cidade de Uberaba Minas Gerais, em 16 de julho de 1916. Fez os seus estudos primários, no Colégio Santa Filomena, em Araxá-MG, e no Ginásio Catarinense em Florianópolis-SC, e o segundo grau, no Ginásio Catarinense e no Colégio Săo José, no Rio de Janeiro-RJ.

Diplomou-se, em 1938, médico, pela Faculdade de Medicina da Universidade Federal do Rio de Janeiro, época denominada Faculdade Nacional de Medicina da Universidade do Brasil.

No decorrer da sua vida profissional, fez diferentes cursos como:

- Esquistosomose Experimental, na Escola de Medicina da Universidade de São Paulo-SP;

- Planejamento em Saúde Pública, na Faculdade de Higiene e Saúde Pública da Universidade de São Paulo;

- Leprologia, no Departamento de Leprologia e Profilaxia da Lepra do Estado de Săo Paulo;

- Motivação e Personalidade, na Universidade Católica de São Paulo;

- Micologia Médica, no Departamento de Microbiologia da Faculdade de Medicina da Universidade de São Paulo.

O Dr. Paulo teve, também, a oportunidade de fazer estágios, especialização, no exterior. Estes estágios foram sobre:

- Enterobacteriaceae, no Instituto de Higiene de Montevideo - Uruguai;

- Metodologia de Pesquisa Biológica, no "Ortho Research Foundation - Raritan, New York, USA".

Quando da Organização do Serviço do Controle da Lepra no Brasil, foi-lhe concedida uma bolsa de estudos por fundações Americanas, para visitar os serviços de lepra da Venezuela e Equador.

Participou de expedições cientificas nos paises da América do Sul, notadamente: Argentina, Chile, Colômbia, Curaçao, Panamá e Paraguai. No Brasil, fez também excursōes, nos Vales dos Rios Araguaia, Paracatu e Jurema.

Como professor, o Dr. Paulo exerceu a Cátedra, no 29 Grau e na Univerisidade. Assim é que ele foi professor de Ciências Naturais, no Colégio São Luís, na Cidade de Săo Paulo de 1939-1943. Na Cátedra Universitária, o seu desempenho se deu como Professor-Assistente, na cadeira de Bioquímica, na Faculdade de Medicina na Universidade de Sorocoba, em 1953. Foi, também, Professor Titular da cadeira de Microbiologia na Universidade Católica de Campinas,

1 - Instituto Nacional de Pesquisas da Amazônia - INPNCPPF - Caixa Postal 478 - 69011 - Manaus, AM

Acta Amazonica, 22 (1): 177 - 180. 1992. 
no Estado de São Paulo, entre 1954-1964. Lecionou Administraçăo na Universidade Católica do Estado de São Paulo entre 1964-1968 e vários cursos sobre Leprologia, sob os auspícios do Antigo Serviço Nacional de Lepra, do Ministério da Saúde e do Departamento de Profilaxia da Lepra, do Estado de Sắo Paulo.

No aprendizado da sua profissão de médico, o Dr. Paulo ainda como estudante de medicina, foi Acadêmico/Auxiliar da cadeira de Ciências Médicas da Faculdade de Medicina, da antiga Universidade do Brasil, na Cidade do Rio de Janeiro, em 1936. No ano subsequente, foi Acadêmico Auxiliar residente da mesma disciplina e en 1938, tornou-se Professor Auxiliar.

Prestou o serviço militar, no Exército em 1945, saindo no posto de 19 Tenente Médico.

Ja diplomado, trabalhou como Microbiologista, no Instituto Adolfo Lutz, na Cidade de Campinas em 1951 e, em 1952, assumiu a chefia do Laboratório de Microbiologia, do mesmo Instituto, onde permaneceu até 1956. De lá saindo, tornou-se Diretor do Departamento da Criança do EStado de São Paulo e nessa função permaneceu de 1957-1958. Daí veio a ser, Diretor do Dispensário para o Interior do Estado de Săo Paulo, e depois dos Serviços de Profilaxia de Lepra, onde permaneceu desde 1963-1969.

Fora estas atividades administrativas o Dr. Paulo tomou parte de vários comitês, onde sempre teve funções de destaque, tais como: Presidente do Comitê Permanente para Padronização de Material Impresso Usado, no Departamento de Sanidade e Dermatologia do Estado de São Paulo, em 1967; Membro do Comi tê Permanente do Planejamento da Lepra, na região da Grande Săo Paulo; Membro para Estudo das Condições Necessárias, para a Instalação de Centros de Saúde, no Estado de São Paulo; Membro do Comitê de Planejamento do Controle da Lepra, em todo o Estado de São Paulo; Membro do Comitê para o Planjamento das Atividades do Departamento de Dematologia Sanitária do mesmo Estado; Membro do Comitê Organizacional da Divisão Regional de Saúde da Grande São Paulo.

Com este rico curriculum e já com 52 anos, ele assumiu a direção do INPA trazido pela mão do Vice-Presidente do $\mathrm{CNPq}$, naquela época, o Dr. Vinícius da Silveira Grillo. Segundo correspondência dele a nós dirigida, o Dr. Paulo afirmava: "0 que eu fiz em Manaus foi fruto de um verdadeiro amor pela Amazônia, para onde me mudei, efetivamente, com minha família, aí morando cinco anos, sem ponte aérea". Prática corrente dos diretores que o antecederam.

Este amor, foi representado por um fausto de realizações, tanto no plano da implementação da pesquisa omo em obras materiais.

Quando ele chegou a Manaus, o Governo Militar tinha para o INPA duas propostas: a primeira, simplesmente, extingui-10, porque, tanto hoje como ontem, perdurava para os novos governantes, que no INPA predominava o empreguismo, nepotismo, funcionários fantasmas, etc. ... preconceitos estes, que infelizmente, o brasileiro que trabalha para o setor público toda vez que assume um novo governante, tem que suportar; a segunda proposta era transferí-lo para Belém.

De acordo com o próprio Dr. Paulo, o professor Grillo tinha profunda sensibilidade politica e advertiu-lhe que ainda não havia nenhuma decisão tomada e estimulou-lhe a lançar uma terceira alternativa, que foi, por sua decisão a permanência do INPA, em Manaus. 0 motivo, como ele próprio confessara, foi uma pleiade de funcionários, que ele encontrou no INPA, remanescentes da sacrificada gestão do Dr. Djalma da Cunha Batista e que foram, na opinião do $\mathrm{Dr}$. Paulo, os baluartes da existência do INPA e fonte de inspiração para sua argumentação, da permanência do INPA em Manaus.

Decidida esta questão, o. Dr. Paulo foi à luta em busca de recursos, visando a independência 
orçamentária da Instituição. Naquela época, o CNPq tinha uma única rubrica denominada Pesquisas na Amazônia, e, dali saíam os recursos das pesquisas para o INPA e Museu Goeldi. 0 total parecia substancial, mas dividido entre as duas organizações, tornava-se insuficiente. $0 \mathrm{Dr}$. Paulo bateu-se incansavelmente e conseguiu a independência de verbas tanto para o INPA como para o Museu Goeldi, que naquele momento, era subordinado ao INPA.

Outra grande obra do Dr. Paulo foi a construção, em tempo record, do Campus do INPA. Quando ele assumiu a direção, a sede do Instituto era localizada no centro da cidade, em um prédio alugado da Santa Casa de Misericórdia de Manaus. Ele questionou junto ao Governo do Estado e conseguiu a doação da área, onde hoje, se situa, o principal Campus. Os recursos para a construção ele obteve da Superintendência do Desenvolvimento da Amazônia - SUDAM, e - arquiteto contratado para elaborar, acompanhar e fiscalizar o projeto foi Severiano Mário Porto, que naquela época já demonstrava criatividade e fez do Campus do INPA um modelo de como harmonizar a intervençăo humana com a natureza. Hoje o Campus do INPA é um oásis para a cidade de Manaus. A administração da construção foi uma das mais baratas. Resumia-se ao Diretor, Administrador, Contador e o Arquiteto Fiscal. 0 corpo de pessoal de apoio era constituído pelos próprios funcionários e năo houve nenhum murmúrio de escândalo, apesar das somas elevadas envolvidas.

Ao mesmo tempo, em que o Dr. Paulo mantinha em marcha a construção do Campus, ele conseguia, a Fundo Perdido do Banco Nacional de Desenvolvimento-BNDES, recursos para equipar os laboratórios. Assim, todos os laboratórios por ele construídos foram parcial ou totalmente equipados.

Outra frente, que o Dr. Paulo atuou de forma contundente foi a construção do ancoradouro dos barcos do INPA, ben como iniciou a construção da nossa frota fluvial: primeiro o barco, Marupiara, singrou os rios da Amazônia, em excursões científicas, que na sua gestão eram constantes e normais.

0 Dr. Paulo, também construiu novas instalações, nas reservas florestais do INPA, que ofereciam comodidade aos pesquisadores residentes e visitantes. No seu tempo, o Enge florestal responsável pela Reserva, era obrigado a residir na Reserva.

Fora estas obras, estritamente de infraestrutura, ele criou ainda em sua fértil gestão a Acta Amazonica, para publicar toda a produção científica do Instituto, uma vez que até a sua chegada, as publicações do INPA se davam através de Boletins seriados por assunto. A Acta Amazonica teve tăo boa aceitação, que mesmo atravessando inúmeros percalços vem se mantendo e hoje é leitura obrigatória, para qualquer estudioso, que queira se debruçar sobre a Amazônia e está na estante das bibliotecas das Universidades do Globo.

Em termos de recrutamento de pesquisadores para o Instituto o Dr. Paulo foi também bastante criativo. Criou o PIATÃ, uma analogia à palavra indigena, que significa forte, mas cujo significado literal era: Programa Intensivo de Adestramento en para o Trabalho na Amazônia". Este programa consistia em recrutar jovens recém-formados, nas Universidades da Amazônia Legal, ministrar cursos básicos de metodologia de pesquisas, informar-lhes sobre as atividades do INPA e realizar excursões terrestres e fluviais de adestramento. Este programa foi muito ben sucedido e rendeu bons frutos, porque dos grandes expoentes das pesquisas, no INPA, hoje dele se originaram.

Outro grande marco da administração do Dr. Paulo foi a criação do Curso de Pós-Graduação, a nivel de Mestrado, em Botánica Tropical. Para organizá-1o e dirigílo ele convocou o Dr. G. T. Prance, na época do New York Botanical Garden. As melhores lentes da ciência nacional e intrnacional ministraram aulas neste curso. Entre os internacionais os Drs. Kubitzk, Dobizanski e outros; Paulo 
Alvim, Nanuza Menezes e Italo Falesi entre os brasileiros. Como alunos, ele deu prioridade a pesqui sadores que jă trabal havam no INPA e que não podiam se ausentar de Manaus, por dificuldades óbvias. Assim, vărios pesquisadores tiveram oportunidade de se titularem sem sair de Manaus, cursando uma das pós-graduaçáo mais eficientes do Brasil.

A gestão do Or. Paulo, no INPA, foi de 1969 - 1974. Daqui ele saiu para ser Ministro da Saúde no Governo do Presidente Ernesto Geisel, mas, isto é outra história, também rica de êxi to e proficuidade.

Para aqueles fucionários e psquisadores, que foram em carreata deixá-lo, no Aeroporto ele legava liçōes de ideal ismo, desprendimento, tenacidade, sinceridäds, confiança, espírito de colaboração, de paciência, independência, altivez, realismo, pioneirismo, coragem, criatividade e sobretudo um profundo amor pela pesquisa e pelo INPA.

Por tudo que fez nesta vida terrena, Dr. Paulo seguiu o paradigma do Apóstolo, e combateu um bom combate e as sementes do seu trabalho geraram tipos frutos duradouros. Este homem era de inabalável estrutura moral. Mesmo quando o câncer the consumia a vida, em cadeira de rodas ele nos escrevia dizendo: "lutando para conservar a vida que me foi confiada como um dom de Deus, mas sem temer a morte que é simplesmente a última página, senão a apoteose da vida".

Descanse em paz grande mestre, sua lembrança há de permanecer indelével no INPA, mesmo que a memória curta dos homens nảo permita, mas ela será perene nas paredes dos prédios, no pipetar da soluçăo, no barulho das máquinas e nas flores das árvores aqui plantadas. 